KANSAS JOURNAL of MEDICINE

\section{Second Generation Patient Specific Total Knees Demonstrate a Higher Manipulation Rate Compared with "Off-the-shelf" Implants}

Paul R. Haeder, M.D. ${ }^{1}$,

Alexander C.M. Chong, MSAE, MSME, 1,2,

Tarun Bhargava, M.D. ${ }^{1,3}$

${ }^{1}$ University of Kansas School of Medicine-Wichita,

Department of Orthopaedics, Wichita, KS

${ }^{2}$ Via Christi Health

Department of Graduate Medical Education-Orthopaedics

Surgery, Wichita, KS

${ }^{3}$ Mid-America Orthopedics, Wichita, KS

\section{ABSTRACT}

Introduction. Patient specific total knee arthroplasty (TKA) theoretically provides a more accurate fit to the native knee but may have difficulty achieving full range of motion (ROM) post-operatively. Post-operative ROMdata were compared between patients who underwent cemented patient-specific cruciate-retaining (PSCR) and standard cemented posterior-stabilized (SPS) TKAs.

Methods. PSCR and SPS TKAs that were performed from January 2014 to September 2015 by the same surgeon using the same postoperative protocols at two selected facilities were reviewed. Twoand six-week post-operative ROM data were obtained and the number of patients with knee flexion less than $110^{\circ}$ was recorded.

Results. Twenty-one patients in the PSCR group and 57 patients in the SPS group were included. The percentage of patients with knee flexion less than $110^{\circ}$ was similar in both groups preoperatively $(10 \%$ vs $14 \%, \mathrm{p}=0.60)$ and two-week post-operatively $(57 \%$ vs $68 \%, p=0.35)$. However, at six-week post-operatively there was significant difference $(29 \%$ vs $7 \%, p=0.01)$.

Conclusions. These results provide evidence to alert orthopaedic surgeons when using these patient specific implants versus conventional TKA methods. Patients whose TKA was performed using patient specific cutting guides struggled to obtain $110^{\circ}$ of knee flexion. Close monitoring, aggressive physical therapy, and early manipulation are recommended when using patient specific cutting guides and custom total knee implants. Further evaluation in a larger group of patients is warranted. KS J Med 2016;9(4):88-92.

\section{INTRODUCTION}

Total knee arthroplasty (TKA) is a successful surgical intervention for addressing pain and improving patient function. It is one of the most common orthopaedic procedures performed and whose demand continues to increase..$^{1-4}$ With the increasing demand comes a focus on ways to achieve a superior outcome. Poor alignment is a well-known risk factor for implant failure ${ }^{5-23}$ which has led to improvements in surgical technique, instrumentation, and implant design..$^{24,25}$ One innovation is the use of patient-specific or custom cutting-blocks and custom implants, which theoretically provide a more accurate fit to the contour of the native knee, ${ }^{20,26-30}$ thus allowing for a superior functional outcome and more efficient use of intraoperative resources.

Patient specific total knee replacements have been designed using computer technology utilizing preoperative magnetic resonance imaging (MRI) or computed topography (CT) to construct a three-dimensional representation of the knee. These data are used to create single-use patient-specific cutting-blocks for both the femur and tibia, which results in more accurate bone cuts for acceptable mechanical alignment and soft tissue balancing without the intra-operative reliance on fixed anatomical landmarks that often are distorted secondary to chronic arthritic changes (i.e., osteophytes). Additionally, these systems allow either predetermination of implant sizes or customized implants for each patient for both the femur and tibia prior to the operation.

Several studies compared these patient-specific instrumentations with standard instrumentation in terms of cost-effec-

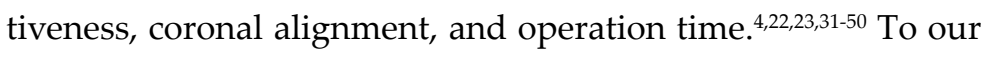
knowledge, however, the outcomes of these implants have not been as well studied. ${ }^{4,37,39} \mathrm{We}$, therefore, retrospectively reviewed consecutive patients undergoing cemented patient-specific cruciate-retaining (PSCR) TKA and compared those patients to those who received a standard cemented posterior-stabilized (SPS) TKA, focusing on rates of postoperative knee manipulation under anesthesia (MUA). At the time of the study, a posterior stabilized custom knee replacement was not available on the market.

\section{PATIENTS AND METHODS}

Institutional review board approval was obtained for the study. A retrospective chart review was performed looking at consecutive PSCR TKAs from January 2014 through September 2015 utilizing the ConforMIS I-Total G2 TKA system (ConforMIS, Inc, Bedford, MA; PSCR group). Patients who underwent SPS TKA during that same time period by the same surgeon were selected, based on the inclusion criteria, to serve as a control group, and the number of patients for this group was selected 3.5 times more than the PSCR group to reduce the percentage of outliers and, therefore, obtain better statistical analysis. In this SPS group, the implant was either Stelkast (Proven Gen-Flex, McMurray, PA) or Zimmer Gender Solutions NexGen (Zimmer, Inc., Warsaw, IN), ATTUNE (DePuy Synthes, Warsaw, IN), or Donjoy Motivation PS (Vista, CA). These two groups (PSCR and SPS groups) were operated on at two surgical centers.

Subject Selection. Inclusion criteria were PSCR TKAs and SPS TKAs performed from January 2014 through September 2015 by the lead surgeon at the two selected facilities. Patients selected were those with the principal diagnosis of osteoarthritis who underwent primary TKA. Patients with a history of trauma and/or a history of surgery on the operative knee also were included as long as there was no form of retained hardware. Since the production of the patient specific cutting guides was dependent on the quality of the preoperative CT, it was determined that the presence of hardware may interfere with the 
KANSAS JOURNAL of MEDICINE

PATIENT SPECIFIC TOTAL KNEES COMPARED WITH

"OFF-THE-SHELF" IMPLANTS

continued.

generation of accurate guides. SPS TKA patients were selected based on similar age, side, deformity, diagnosis, and preoperative range of motion with patients who underwent PSCR TKAs.

Exclusion criteria included all patients who underwent PSCR or SPS TKAs outside of January 2014 through September 2015 and not by the lead surgeon at the two selected facilities. Patients were excluded from the study if they underwent the pre-operative planning but the patient specific cutting guides were not utilized during the procedure.

Patient-Specific TKA Surgical Technique. Pre-operative planning was performed as described by the manufacturer's protocol. Prior to surgery, each patient had CT images of the operative lower extremity from hip to ankle performed. The CT imaging data were provided to the manufacturer who was responsible for the custom fabrication of the femoral and tibial patient specific cutting guides and custom total knee implants. Scheduling of the operation was made once the patient specific cutting guides and implants were provided by the manufacturer. This pre-operative planning usually required at least seven weeks from the time of the initial visit.

The surgery was performed through a traditional medial parapatellar approach under tourniquet control. For the PSCR TKA, the posterior cruciate ligament (PCL) was left intact, whereas for the SPS TKA the PCL was resected. Once bony exposures were achieved, and prior to any revision or resection of bone, the patient specific cutting guides were placed as manufacturer guidelines directed. The guides were pinned after appropriate placement. These initial steps were performed in similar fashion for both the femur and the tibia. In each of the operations, the femur was addressed first. After standard cuts were made, the trial femoral implant was placed and the surgeon evaluated femoral component size, femoral anterior-posterior translation, femoral component rotation, and femoral proximal-distal translation.

A similar procedure was performed on the tibia including placement of patient specific cutting guide and standard cuts. Following completion of the initial bone cuts, the tibial trial component was placed. Component placement was evaluated for appropriate tibial component size, tibial slope, tibial rotation, and tibial proximal-distal translation.

Manipulation under Anesthesia (MUA) Technique. Subjects who had knee flexion less than $110^{\circ}$ by six-week post-operative were selected for MUA. A previous study indicated that patients with knee flexion less than $110^{\circ}$ were not able to kneel, ${ }^{51}$ and kneeling is one of the important functions of the knee joint required for many activities of daily living and in certain occupations. ${ }^{52,53}$ Therefore, this study defined knee flexion less than $110^{\circ}$ as the criterion for MUA. The procedure was performed with the patient taken to the operating room where general anesthesia was induced. After adequate muscle relaxation was achieved, the ipsilateral hip was flexed to $90^{\circ}$. To minimize the risk of iatrogenic fracture, the surgeons' hands were placed on the distal femur and proximal tibia close to the knee joint line. Steady progressive loading was applied to the tibia to flex the knee until audible and palpable break of adhesions were felt. The final range of motion (ROM) then was recorded. Patients underwent aggressive physical therapy in the post-operative period.

Data Collection. A chart review was performed of the pre-operative assessment and included documentation of gender, age, height, weight, body mass index (BMI), side of the knee, and deformities in the knee. Pre-operative ROM also was obtained from the history and physical. All patients underwent the same post-operative protocol, including post-operative physical therapy. Post-operative ROM was obtained at two- and six-weeks after surgery. All post-operative measurements were taken by a physical therapist with the aid of a goniometer to ensure accurate measurements. If the patient underwent a subsequent MUA, it was recorded along with post-MUA ROM. Two- and six-week post-operative ROM data were reviewed and the number of patients with knee flexion less than $110^{\circ}$ was recorded.

\section{STATISTICAL ANALYSIS}

The chi-square test using SPSS software (Version 19.0; SPSS Inc, Chicago, IL) was used to determine if there were any observed differences between the PSCR and SPS TKAs with respect to knee flexion pre-operatively and at two- and six-week post-operatively. The level of significant difference was defined as $p<0.05$.

\section{RESULTS}

There were a total of 96 patients that met the inclusion criteria, 22 patients (28\%) in the PSCR group and 74 patients (72\%) in the SPS group. One of the 22 patients in the PSCR group was excluded due to a popliteal artery thrombosis that subsequently led to above knee amputation in the immediate post-operative period. Seventeen $(23 \%)$ out of the 74 patients in the SPS group were excluded due to lack of follow-up information, resulting in a total of 57 patients for the SPS group.

Table 1 summarizes the demographic profile of the patients for this study. Of the 21 patients in the PSCR group, 14 were females (67\%) and 7 were males (33\%). In the 57 patients in the SPS group, 41 were females $(72 \%)$ and 16 were males $(28 \%)$. The mean age for PSCR and SPS groups were $59 \pm 10$ years (range: $36-72$ years) and $65 \pm 10$ years (range: 47 - 89 years), respectively. The mean BMI for PSCR group was $30.7 \pm 6.7 \mathrm{~kg} / \mathrm{m} 2$ (range: $21.6-46.8 \mathrm{~kg} / \mathrm{m} 2$ ), and $35.0 \pm 7.0 \mathrm{~kg} / \mathrm{m} 2$ (range: 23.0 - $51.6 \mathrm{~kg} / \mathrm{m} 2$ ) for the SPS group.

The summary of patients with knee flexion less than $110^{\circ}$ is shown in Table 2. The SPS group had a higher percentage of patients with knee flexion less than $110^{\circ}$ pre-operatively $(14 \%)$ compared to the PSCR group (10\%). Statistically, there was no difference between these two groups $(p=0.60)$. At the two-week post-operative visit, this trend continued with $68 \%$ of 57 patients in the SPS group versus 12 (57\%) of 21 patients in the PSCR group $(p=0.35)$. However, at the six-week post-operative period, this trend significantly changed with $4(7 \%)$ out of 57 patients in the SPS group having less than $110^{\circ}$ of knee flexion compared 
KANSAS JOURNAL of MEDICINE

PATIENT SPECIFIC TOTAL KNEES COMPARED WITH

"OFF-THE-SHELF" IMPLANTS

continued.

with $6(29 \%)$ out of 21 patients in the PSCR group $(\mathrm{p}=0.01)$. The SPS group went from $68 \%$ of patients with less than $110^{\circ}$ of flexion to only $7 \%$ during the two- to six-week post-operative time course. In comparison, the PSCR group went from 57\% to $29 \%$.

Table 1. Patient demographics.

\begin{tabular}{|c|c|c|c|}
\hline & & $\begin{array}{l}\text { PSCR Group } \\
(\mathbf{N}=21)\end{array}$ & $\begin{array}{l}\text { SPS Group } \\
(\mathbf{N}=57)\end{array}$ \\
\hline \multirow{2}{*}{ Gender } & Female & $14(67 \%)$ & $41(72 \%)$ \\
\hline & Male & $7(33 \%)$ & $16(28 \%)$ \\
\hline \multicolumn{2}{|c|}{$\begin{array}{c}\text { Age (years, mean } \pm \text { SD) } \\
\text { (range) }\end{array}$} & $\begin{array}{c}59 \pm 10 \\
(36-72)\end{array}$ & $\begin{array}{c}65 \pm 10 \\
(47-89)\end{array}$ \\
\hline \multicolumn{2}{|c|}{$\begin{array}{c}\mathrm{BMI}\left(\mathrm{kg} / \mathrm{m}^{2}, \text { mean } \pm \mathrm{SD}\right) \\
(\text { range })\end{array}$} & $\begin{array}{c}30.7 \pm 6.7 \\
(21.6-46.8)\end{array}$ & $\begin{array}{c}35.0 \pm 7.0 \\
(23.0-51.6)\end{array}$ \\
\hline \multicolumn{2}{|c|}{$\begin{array}{l}\text { Height (inches, mean } \pm \text { SD) } \\
\text { (range) }\end{array}$} & $\begin{array}{c}67 \pm 4 \\
(61-75)\end{array}$ & $\begin{array}{c}66 \pm 4 \\
(56-74)\end{array}$ \\
\hline \multicolumn{2}{|c|}{$\begin{array}{l}\text { Weight (lbs., mean } \pm \text { SD) } \\
\text { (range) }\end{array}$} & $\begin{array}{c}196 \pm 53 \\
(126-319)\end{array}$ & $\begin{array}{c}216 \pm 51 \\
(133-337)\end{array}$ \\
\hline \multirow{2}{*}{ Side } & Left & $7(33 \%)$ & $26(46 \%)$ \\
\hline & Right & $14(67 \%)$ & $31(54 \%)$ \\
\hline
\end{tabular}

Table 2. Patients with knee flexion less than $110^{\circ}$.

\begin{tabular}{|c|c|c|c|}
\hline & $\begin{array}{c}\text { PSCR Group } \\
\text { (N = 21) }\end{array}$ & $\begin{array}{c}\text { SPS Group } \\
\text { (N = 57) }\end{array}$ & p value \\
\hline Pre-operative & $2(10 \%)$ & $8(14 \%)$ & 0.60 \\
\hline 2-week post-operative & $12(57 \%)$ & $39(68 \%)$ & 0.35 \\
\hline 6-week post-operative & $6(29 \%)$ & $4(7 \%)$ & 0.01 \\
\hline
\end{tabular}

All six patients in the PSCR group who had less than $110^{\circ}$ of flexion six-week post-operatively underwent a MUA. Five significantly improved (average: 24 degrees, range: 10 - 40 degrees) their knee flexion to at least $115^{\circ}$. The other ultimately underwent a second MUA.

Only one of the four patients in the SPS group with less than $110^{\circ}$ of flexion six-week post-operatively underwent a MUA. The patient improved knee flexion from 95 to $110^{\circ}$. One patient had a post-operative stroke severely affecting the operative extremity in the immediate post-operative period. This patient ended up with $90^{\circ}$ of flexion but did not have a MUA secondary to lack of motor function in the operative extremity. The other two patients presented with knee flexion of $105^{\circ}$ at six-week post-operatively; both patients were counseled but elected not to undergo a MUA and improved ROM with further therapy. They had no functional limitations at that time.

\section{DISCUSSION}

Patients whoseTKAs were performed using cruciate retaining patient specific implants with custom cutting guides struggle to obtain knee flexion of $110^{\circ}$, which potentially could restrict patients from kneeling. Caution should be taken when using patient specific cutting guides and custom total knee implants. Patient specific or custom implants have the theoretical advantage of providing a more accurate fit to the contour of the na- tive knee which is hoped will allow for a superior functional outcome, but they were not a substitute for careful preoperative planning, good clinical and intraoperative judgment, appropriate soft tissue balancing, and precise implantation technique.

Bali and colleagues ${ }^{33}$ prospectively studied 32 TKAs performed in 29 patients with MRI-based custom cutting guides. Their results showed that 29 of the 32 knees had a mechanical axis restored to within $3^{\circ}$ of neutral, and they concluded that this technology can be used safely in most cases of osteoarthritis of the knee. However, they did not study the functional outcome of these patients. In our study, the rate of knee flexion less than $110^{\circ}$ in the PSCR group was significantly higher compared with the SPS group. There is no clear evidence for this lack of knee flexion in the PSCR group. It is suspected that the close fit of the implants may place the patient at risk for stiffness. There also could be errors in the data input or in the manufacturing of the cutting-blocks and implants which could lead to difficulty with ROM. Another possibility for the lack of post-operative knee flexion may be the over reliance on the custom design and lack of attention to proper soft tissue balancing. The patient specific cutting guides and implants produce accurate and precise limb alignment. ${ }^{22}$ Static alignment is unfortunately only one variable that can affect TKA performance. One of the major disadvantages of using the custom guides and implants is that no other instrument can be used intra-operatively to judge proper bony cuts and soft tissues balancing. ${ }^{22}$

There are several limitations of this study. First, this was a retrospective chart review utilizing information that had to have been documented accurately in the medical record. Second, this study had a small sample size for the PSCR group, which prevents applying tests of significance due to a low power. The low number of procedures performed in the PSCR group was unavoidable because the treating surgeon stopped using the implant secondary to concerns over stiffness as the overall functional outcomes were found not to be satisfactory as the study progressed. This study compared cruciate retaining (CR) TKAs to the posterior stabilized (PS) TKAs. These designs are based on the retention or sacrifice of the posterior cruciate ligament. Several other cohort studies and randomized controlled trial studies have shown no difference in flexion or range of motion between the two designs. ${ }^{54-64}$ Given the available research models, we feel that the data are valid for the current investigation. One other weakness of the present study is the ROM measurements were taken by different therapists at different places. Nevertheless, this study contributes to the available literature on the functional outcomes of knee flexion for patient-specific total knee replacements. Further evaluation in a larger group of patients is required to resolve the question of functional results for the patient specific CR TKA. 
KANSAS JOURNAL of MEDICINE

PATIENT SPECIFIC TOTAL KNEES COMPARED WITH

\section{“OFF-THE-SHELF” IMPLANTS}

\section{CONCLUSION}

The findings of this study provide additional evidence on the functional outcomes when using patient specific cutting guides/implants in TKA. Close monitoring, aggressive physical therapy, and early manipulation is recommended when using patient specific cutting guides and custom total knee implants.

\section{ACKNOWLEDGEMENT}

The authors wish to thank George Lucas, M.D. for his revision and critical comments on the papers.

\section{REFERENCES}

${ }^{1}$ Kurtz S, Ong K, Lau E, Mowat F, Halpern M. Projections of primary and revision hip and knee arthroplasty in the United States from 2005 to 2030. J Bone Joint Surg Am 2007; 89(4):780-785. PMID: 17403800. 2 Kurtz SM, Ong KL, Schmier J, et al. Future clinical and economic impact of revision total hip and knee arthroplasty. J Bone Joint Surg Am 2007; 89 Suppl 3:144-151. PMID: 17908880. ${ }^{3}$ Iorio R, Robb WJ, Healy WL, et al. Orthopaedic surgeon workforce and volume assessment for total hip and knee replacement in the United States: Preparing for an epidemic. J Bone Joint Surg Am 2008; 90(7):1598-1605. PMID: 18594111. ${ }^{4}$ Lachiewicz PF, Henderson RA. Patient-specific instruments for total knee arthroplasty. J Am Acad Orthop Surg 2013; 21(9):513-518. PMID: 23996982. ${ }^{5}$ Ritter MA, Faris PM, Keating EM, Meding JB. Postoperative alignment of total knee replacement. Its effect on survival. Clin Orthop Relat Res 1994; (299):153-156. PMID: 8119010. ${ }^{6}$ Kumar PJ, Dorr LD. Severe malalignment and soft-tissue imbalance in total knee arthroplasty. Am J KneeSurg 1997;10(1):36-41.PMID:9051176. ${ }^{7}$ Ritter MA, Montgomery TJ, Zhou H, Keating ME, Faris PM, Meding JB. The clinical significance of proximal tibial resection level in total knee arthroplasty. Clin Orthop Relat Res 1999; (360):174-181. PMID: 10101323. ${ }^{8}$ Green GV, Berend KR, Berend ME, Glisson RR, Vail TP. The effects of varus tibial alignment on proximal tibial surface strain in total knee arthroplasty: The posteromedial hot spot. J Arthroplasty 2002; 17(8):1033-1039. PMID: 12478515. ${ }^{9}$ Sharkey PF, Hozack WJ, Rothman RH, Shastri S, Jacoby SM. Insall Award paper. Why are total knee arthroplasties failing today? Clin Orthop Relat Res 2002; (404):7-13. PMID: 12439231. ${ }^{10}$ Stulberg SD, Loan P, Sarin V. Computer-assisted navigation in total knee replacement: Results of an initial experience in thirty-five patients. J Bone Joint Surg Am 2002; 84-A Suppl 2:90-98. PMID: 12479344. 11 Krackow KA, Phillips MJ, Bayers-Thering M, Serpe L, Mihalko WM. Computer-assisted total knee arthroplasty: Navigation in TKA. Orthopedics 2003; 26(10):1017-1023. PMID: 14577524. ${ }_{12}$ Bäthis H, Perlick L, Tingart M, Lüring C, Zurakowski D, Grifka J. Alignment in total knee arthroplasty. A comparison of computer-assisted surgery with the conventional technique. J Bone Joint Surg Br 2004; 86(5):682-687. PMID: 15274263. ${ }^{13}$ Berend ME, Ritter MA, Meding JB, et al. Tibial component failure mechanisms in total knee arthroplasty. Clin Orthop Relat Res 2004; (428):26-34. PMID: 15534515. ${ }^{14}$ Anderson KC, Buehler KC, Markel DC. Computer assisted navigation in total knee arthroplasty: Comparison with conventional methods. J Arthroplasty 2005; 20 (7 Suppl 3):132-138. PMID: 16214014. ${ }^{15}$ Werner FW, Ayers DC, Maletsky LP, Rullkoetter PJ. The effect of valgus/varus malalignment on load distribution in total knee replacements. J Biomech 2005; 38(2):349-355. PMID: 15598463. ${ }_{16}$ Sikorski JM. Alignment in total knee replacement. J Bone Joint Surg Br 2008; 90(9):1121-1127. PMID: 18757949. 17 Fang DM, Ritter MA, Davis KE. Coronal alignment in total knee arthroplasty: Just how important is it? J Arthroplasty 2009; 24(6 Suppl):39-43. PMID: 19553073.
18 Parratte S, Pagnano MW, Trousdale RT, Berry DJ. Effect of postoperative mechanical axis alignment on the fifteenyear survival of modern, cemented total knee replacements. J Bone Joint Surg Am 2010; 92(12):2143-2149. PMID: 20844155. ${ }^{19}$ Lombardi AV Jr, Berend KR, Ng VY. Neutral mechanical alignment: A requirement for successful TKA: affirms. Orthopedics 2011; 34(9):e504-506. PMID: 21902145. ${ }^{20}$ Lombardi AV Jr, Frye BM. Customization of cutting blocks: Can this address the problem? Curr Rev Musculoskelet Med 2012; 5(4):309-314. PMID: 23054623. ${ }^{21}$ Srivastava A, Lee GY, Steklov N, Colwell CW Jr, Ezzet KA, D'Lima DD. Effect of tibial component varus on wear in total knee arthroplasty. Knee 2012; 19(5):560-563. PMID: 22206820. ${ }^{22} \mathrm{Ng}$ VY, DeClaire JH, Berend KR, Gulick BC, Lombardi AV Jr. Improved accuracy of alignment with patient-specific positioning guides compared with manual instrumentation in TKA. Clin Orthop Relat Res 2012; 470(1):99-107. PMID: 21809150. ${ }^{23}$ Daniilidis K, Tibesku CO. A comparison of conventional and patient-specific instruments in total knee arthroplasty. Int Orthop 2014; 38(3):503-508. PMID: 23900384. ${ }_{24}$ Slamin J, Parsley B. Evolution of customization design for total knee arthroplasty. Curr Rev Musculoskelet Med 2012; 5(4):290-295. PMID: 23054622. ${ }^{25}$ Heyse TJ, Tibesku CO. Improved femoral component rotation in TKA using patient-specific instrumentation. Knee 2014; 21(1):268-271. PMID: 23140905. ${ }^{26}$ Harrysson OL, Hosni YA, Nayfeh JF. Custom-designed orthopedic implants evaluated using finite element analysis of patientspecific computed tomography data: Femoral-component case study. BMC Musculoskelet Disord 2007; 8:91. PMID: 17854508. ${ }^{27}$ Howell SM, Kuznik K, Hull ML, Siston RA. Results of an initial experience with custom-fit positioning total knee arthroplasty in a series of 48 patients. Orthopedics 2008; 31(9):857-863. PMID: 18814593. ${ }^{28}$ Lombardi AV Jr, Berend KR, Adams JB. Patient-specific approach in total knee arthroplasty. Orthopedics 2008; 31(9):927-930. PMID: 18814618. ${ }^{29}$ White D, Chelule KL, Seedhom BB. Accuracy of MRI vs CT imaging with particular reference to patient specific templates for total knee replacement surgery. Int J Med Robot 2008; 4(3):224-231. PMID: 18680138. ${ }^{30}$ Spencer BA, Mont MA, McGrath MS, Boyd B, Mitrick MF. Initial experience with custom-fit total knee replacement: Intra-operative events and long-leg coronal alignment. Int Orthop 2009; 33(6):1571-1575. PMID: 19099305. ${ }^{31}$ Klatt BA, Goyal N, Austin MS, Hozack WJ. Customfit total knee arthroplasty (OtisKnee) results in malalignment. J Arthroplasty 2008; 23(1):26-29. PMID: 18165024. ${ }^{32}$ Watters TS, Mather RC III, Browne JA, Berend KR, Lombardi AV Jr, Bolognesi MP. Analysis of procedure-related costs and proposed benefits of using patient specific approach in total knee arthroplasty. J Surg Orthop Adv 2011; 20(2):112-116. PMID: 21838072. ${ }^{33}$ Bali K, Walker $\mathrm{P}$, Bruce W. Custom-fit total knee arthroplasty: Our initial experience in 32 knees. J Arthroplasty 2012; 27(6):1149-1154. PMID: 22285230. ${ }^{34}$ Barrack RL, Ruh EL, Williams BM, Ford AD, Foreman K, Nunley RM. Patient specific cutting blocks are currently of no proven value. J Bone Joint Surg Br 2012; 94(11 suppl A):95-99. PMID: 23118393. ${ }^{35}$ Boonen B, Schotanus MG, Kort NP. Preliminary experience with the patient-specific templating total knee arthroplasty. Acta Orthop 2012; 83(4):387-393. PMID: 22880715. ${ }^{36}$ Conteduca F, Iorio R, Mazza D, et al. Evaluation of the accuracy of a patient-specific instrumentation by navigation. Knee Surg Sports Traumatol Arthrosc 2013; 21(10):2194-2199. PMID: 22735977. 37 Nunley RM, Ellison BS, Ruh EL, et al. Are patient-specific cutting blocks cost-effective for total knee arthroplasty? Clin Orthop Relat Res 2012; 470(3):889-894. PMID: 22183476. ${ }^{38}$ Nunley RM, Ellison BS, Zhu J, Ruh EL, Howell SM, Barrack RL. Do patient-specific guides improve coronal alignment in total knee arthroplasty? Clin Orthop Relat Res 2012; 470(3):895-902. PMID: 22183477. 39 Noble JW Jr, Moore CA, Liu N. The value of patient-matched instrumentation in total knee arthroplasty. J Arthroplasty 2012; 27(1):153-155. PMID: 21908169. 40 Slover JD, Rubash HE, Malchau H, Bosco JA. Cost-effectiveness analysis of custom total knee cutting blocks. J Arthroplasty 2012; 27(2):180-185. PMID: 21676584. 
KANSAS JOURNAL of MEDICINE PATIENT SPECIFIC TOTAL KNEES COMPARED WITH "OFF-THE-SHELF" IMPLANTS

continued.

${ }^{41}$ Tibesku CO, Innocenti B, Wong P, Salehi A, Labey L. Can CT-based patient-matched instrumentation achieve consistent rotational alignment in knee arthroplasty? Arch Orthop Trauma Surg 2012; 132(2):171-177. PMID: 22006572. 42 Barke S, Musanhu E, Busch C, Stafford G, Field R. Patientmatched total knee arthroplasty: Does it offer any clinical advantages? Acta Orthop Belg 2013; 79(3):307-311. PMID: 23926734. ${ }^{43}$ Chareancholvanich K, Narkbunnam R, Pornrattanamaneewong C. A prospective randomised controlled study of patient-specific cutting guides compared with conventional instrumentation in total knee replacement. Bone Joint J 2013; 95-B(3):354-359. PMID: 23450020. ${ }^{44}$ Hamilton WG, Parks NL, Saxena A. Patient-specific instrumentation does not shorten surgical time: A prospective, randomized trial. J Arthroplasty 2013; 28(8 Suppl):96-100. PMID: 23910821. ${ }^{45}$ Nam D, Maher PA, Rebolledo BJ, Nawabi DH, McLawhorn AS, Pearle AD. Patient specific cutting guides versus an imageless, computer-assisted surgery system in total knee arthroplasty. Knee 2013; 20(4):263-267. PMID: 23347791. ${ }^{46}$ Roh YW, Kim TW, Lee S, Seong SC, Lee MC. Is TKA using patient-specific instruments comparable to conventional TKA? A randomized controlled study of one system. Clin Orthop Relat Res 2013; 471(12):3988-3995. PMID: 23907610. ${ }^{47}$ Stronach BM, Pelt CE, Erickson J, Peters CL. Patient-specific total knee arthroplasty required frequent surgeon-directed changes. Clin Orthop Relat Res 2013; 471(1):169-174. PMID: 22956239. ${ }^{48}$ VundelinckxBJ,Bruckers L, DeMulderK,DeSchepperJ, Van Esbroeck G. Functional and radiographic short-term outcome evaluation of the Visionaire system, a patient-matched instrumentation system for total knee arthroplasty. J Arthroplasty 2013; 28(6):964-970. PMID: 23535285. ${ }^{49}$ Chotanaphuti T, Wangwittayakul V, Khuangsirikul S, Foojareonyos $\mathrm{T}$. The accuracy of component alignment in custom cutting blocks compared with conventional total knee arthroplasty instrumentation: Prospective control trial. Knee 2014; 21(1):185-188. PMID: 23999209. ${ }^{50}$ Victor J, Dujardin J, Vandenneucker H, Arnout N, Bellemans J. Patient-specific guides do not improve accuracy in total knee arthroplasty: A prospective randomized controlled trial. Clin Orthop Relat Res 2014; 472(1):263-271. PMID: 23616267. 51 Palmer SH, Servant CT, Maguire J, Parish EN, Cross MJ. Ability to kneel after total knee replacement. J Bone Joint Surg $\mathrm{Br}$ 2002; 84(2):220-222. PMID: 11922363. ${ }^{52}$ Coggon D, Croft P, Kellingray S, Barrett D, McLaren M, Cooper C. Occupational physical activities and osteoarthritis of the knee. Arthritis Rheum 2000; 43(7):1443-1449. PMID: 10902744. ${ }^{53}$ Cooper C, McAlindon T, Coggon D, Egger P, Dieppe P. Occupational activity and osteoarthritis of the knee. Ann Rheum Dis 1994; 53(2):90-93. PMID: 8129467. ${ }^{54}$ Parsley BS, Conditt MA, Bertolusso R, Noble PC. Posterior cruciate ligament substitution is not essential for excellent postoperative outcomes in total knee arthroplasty. J Arthroplasty 2006; 21(6 Suppl 2):127-131. PMID: 16950074. ${ }_{55}$ Victor J, Banks S, Bellemans J. Kinematics of posterior cruciate ligament-retaining and -substituting total knee arthroplasty: A prospective randomised outcome study. J Bone Joint Surg Br 2005; 87(5):646-655. PMID: 15855366. ${ }^{56} \mathrm{Kim}$ YH, Choi Y, Kwon OR, Kim JS. Functional outcome and range of motion of high-flexion posterior cruciate-retaining and high-flexion posterior cruciate-substituting total knee prostheses. A prospective, randomized study.JBoneJointSurgAm2009;91(4):753-760.PMID:19339558. ${ }^{57} \mathrm{Kim} \mathrm{YH}$, Kim JS, Yoon SH. A recession of posterior cruciate ligament in posterior cruciate-retaining total knee arthrosplasty. J Arthroplasty 2008; 23(7):999-1004. PMID: 18534500. ${ }^{58}$ Wang CJ, WangJW, Chen HS. Comparing cruciate-retaining total knee arthroplasty and cruciate-substituting totalkneearthroplasty:A prospectiveclinicalstudy.ChangGungMedJ2004;27(8):578-585.PMID:15553604. ${ }^{59}$ Chaudhary R, Beaupré LA, Johnston DW. Knee range of motion during the first two years after use of posterior cruciate-stabilizing or posterior cruciate-retaining total knee prostheses. A randomized clinical trial. J Bone Joint Surg Am 2008; 90(12):2579-2586. PMID: 19047702.
60 Tanzer M, Smith K, Burnett S. Posterior-stabilized versus cruciate-retaining total knee arthroplasty: Balancing the gap. J Arthroplasty 2002; 17(7):813-819. PMID: 12375237. ${ }_{61}$ Clark CR, Rorabeck CH, MacDonald S, MacDonald D, Swafford J, Cleland D. Posterior-stabilized and cruciate-retaining total knee replacement: A randomized study. Clin Orthop Relat Res 2001; (392):208-212. PMID: 11716384. ${ }^{62}$ Straw R, Kulkarni S, Attfield S, Wilton TJ. Posterior cruciate ligament at total knee replacement. Essential, beneficial or a hindrance? J Bone Joint Surg Br 2003; 85(5):671-674. PMID: 12892188.

${ }^{63}$ Snider MG, Macdonald SJ. The influence of the posterior cruciate ligament and component design on joint line position after primary total knee arthroplasty. JArthroplasty 2009;24(7):1093-1098. PMID:19027265. ${ }^{64}$ Bercik MJ, Joshi A, Parvizi J. Posterior cruciate-retaining versus posterior-stabilized total knee arthroplasty: A metaanalysis. J Arthroplasty 2013; 28(3):439-444. PMID: 23433255.

Keywords: orthopedics, total knee arthroplasty, knee joint, custom total knee 